\title{
Benefits and Limitations of Lab-on-a-Chip Method over Reversed-Phase High-Performance Liquid Chromatography Method in Gluten Proteins Evaluation
}

\author{
Dragan Živančev, ${ }^{1}$ Daniela Horvat, ${ }^{2}$ Aleksandra Torbica, ${ }^{1}$ Miona Belović, ${ }^{1}$ \\ Gordana Šimić, ${ }^{2}$ Damir Magdić, ${ }^{3}$ and Nevena Đukićc ${ }^{4}$ \\ ${ }^{1}$ Institute of Food Technology, University of Novi Sad, Bulevar Cara Lazara 1, 21000 Novi Sad, Serbia \\ ${ }^{2}$ Agricultural Institute Osijek, Južno Predgrađe 17, 31000 Osijek, Croatia \\ ${ }^{3}$ Faculty of Food Technology, J.J. Strossmayer University of Osijek, Franje Kuhača 18, 31000 Osijek, Croatia \\ ${ }^{4}$ Faculty of Natural Science, University of Kragujevac, Radoja Domanovića 12, 34000 Kragujevac, Serbia
}

Correspondence should be addressed to Aleksandra Torbica; aleksandra.torbica@fins.uns.ac.rs

Received 28 November 2014; Revised 28 January 2015; Accepted 5 February 2015

Academic Editor: Marcone A. L. de Oliveira

Copyright (C) 2015 Dragan Živančev et al. This is an open access article distributed under the Creative Commons Attribution License, which permits unrestricted use, distribution, and reproduction in any medium, provided the original work is properly cited.

RP-HPLC (reversed-phase high-performance liquid chromatography) is widely used to determine the amounts of the different gluten protein types. However, this method is time-consuming, especially at early stages of wheat breeding, when large number of samples needs to be analyzed. On the other hand, LoaC (Lab-on-a-Chip) technique has the potential for a fast, reliable, and automatable analysis of proteins. In the present study, benefits and limitations of Lab-on-a-Chip method over RP-HPLC method in gluten proteins evaluation were explored in order to determine in which way LoaC method should be improved in order to make its results more compliant with the results of RP-HPLC method. Strong correlation $(P \leq 0.001)$ was found between numbers of HMW glutenin peaks determined by LoaC and RP-HPLC methods. Significant correlations $(P \leq 0.05)$ were obtained between percentages of HMW and LMW glutenin subunits calculated with regard to total HMW + LMW area. Even more significant correlation $(P \leq 0.001)$ was found when percentages of individual HMW areas were calculated with regard to total HMW. RPHPLC method showed superiority in determination of gliadins since larger number and better resolution of gliadin peaks were obtained by this method.

\section{Introduction}

In the past decade, much attention has been focused on developing microfluid or Lab-on-a-Chip (LoaC) technique and its application for sensitive biochemical analyses. This system has the potential for a fast, reliable, and automatable analysis in the field of proteins' separation and quantification [1, 2]. Complete analysis of 10 protein samples (number of samples analysed per one chip), including sizing and quantification, lasts for $25 \mathrm{~min}$, including the start-up phase of the instrument [3]. The LoaC method for protein analysis allows the integration of electrophoretic separation, staining, destaining, and fluorescence detection into a single process combined with data analysis. Also, current LoaC method showed quite comparable results with the conventional sodium dodecyl sulfate polyacrylamide gel electrophoresis (SDS-PAGE) in determination of proteins: the linear dynamic range or resolution is superior in case of $\mathrm{LoaC}$ [3], whereas in a study of Torbica et al. [4] LoaC showed superiority over SDS-PAGE in selectivity and sensitivity when Kunitz trypsin inhibitor in soybean was analysed. Today, various LoaC instruments are available and they are often used for determination of gluten proteins [5-10], which are the most responsible for the viscoelastic properties of dough and baking quality of wheat (Triticum aestivum L.) [11].

In the late 90s of the last century, Wieser et al. [12] developed a combined extraction-RP-HPLC procedure for determination of the amounts of the different gluten protein types 
$(\omega$-, $\alpha$-, and $\gamma$-gliadins; high molecular weight (HMW); and low molecular weight (LMW) glutenin subunits) in wheat flour. Wieser et al. $[13,14]$ used the procedure to examine the impact of nitrogen fertilisation on their amounts and ratios in wheat and how they are connected with wheat quality. RP-HPLC technique is quite time-consuming for separation of gluten proteins since analysis time is between 30 and 80 min per sample, whereas the number of samples that can be analyzed daily per instrument is less than 30 . A costeffective method is required in order to meet the demands of increasing number of samples that need to be analyzed at early stages of breeding.

The aim of this study was to determine in which way LoaC method should be improved in order to make its results more compliant with the results of RP-HPLC method. This is of high importance since LoaC method is superior in performance speed but lacks merits of conventional, widely applied methods, and therefore their characteristics should be integrated with LoaC method. Consequently, sample preparation was not unified for these two methods.

\section{Materials and Methods}

2.1. Materials. Examinations have been carried out on nine common wheat (Triticum aestivum L.) cultivars ("Divana," "Aida," "Felix," "Seka," "Renata," "Soissons," "Olimpija," "Vulkan," and "Tihana”) grown in Croatia at the Agricultural Institute in Osijek and nine common wheat cultivars ("Dragana," "Ljiljana," "Pobeda," "Bastijana," "Nevesinjska," "Simonida," "Etida," "Zvezdana," and "NS3-5299/2") grown in Serbia at the Institute of Field and Vegetable Crops in Novi Sad in harvest season 2009.

2.2. Milling. Wheat samples were milled by MLU-202 (Bühler, Uzwil, Switzerland) and the obtained flour was used for further analysis.

2.3. Extraction for LoaC. The percentage of gliadin and glutenin subunits was determined from $30 \mathrm{mg}$ of flour after removal of albumins and globulins. The gliadins were subsequently extracted with $300 \mu \mathrm{L}$ of $70 \%$ ethanol and $200 \mu \mathrm{L}$ was transferred into test tube $(1.5 \mathrm{~mL})$, whereas the rest of the solution was removed for glutenin extraction. After evaporation of ethanol, gliadins were treated with $350 \mu \mathrm{L}$ of $2 \%$ SDS solution containing $5 \% \beta$-mercaptoethanol and afterwards heated for 5 minutes to $100^{\circ} \mathrm{C}$. For extraction of full range of the glutenin subunits the same volume of treatment solution (2\% SDS solution containing 5\% $\beta$-mercaptoethanol and $0.0625 \mathrm{M}$ Tris-base) and temperature conditions was used.

2.4. LoaC. Final solutions of glutenins were prepared by mixing of $4 \mu \mathrm{L}$ of the clarified sample extract with $2 \mu \mathrm{L}$ of Agilent sample buffer and $84 \mu \mathrm{L}$ of deionized water. Separation of proteins was performed using chip electrophoresis technique on Agilent 2100 Bioanalyzer (Agilent Technologies, Santa Clara, CA) with Protein 230 Plus Lab-on-a-Chip kit, which determined molecular weights of proteins in range from 12.5 to $230 \mathrm{kDa}$ (Figure 1). After analysis, every subunit

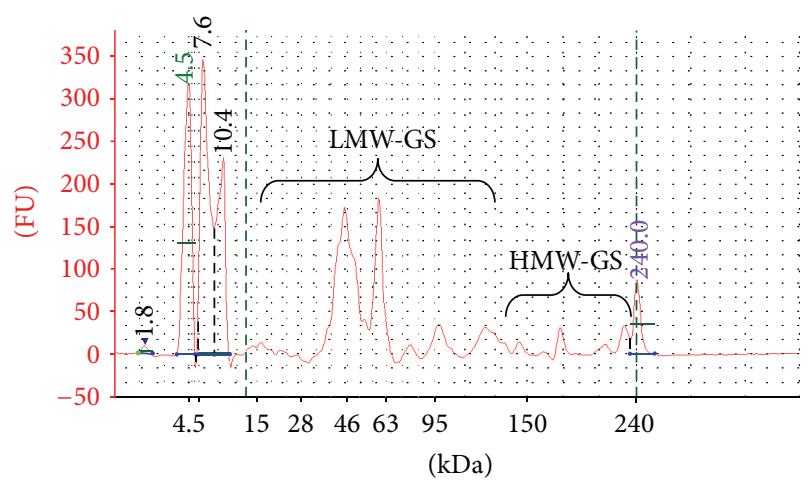

FIGURE 1: Electrophoregram of glutenins of cultivar "Renata."

was manually integrated and their percentage was calculated from the time-corrected area.

2.5. Extraction for RP-HPLC. The wheat proteins extraction from wholemeal flour (Retsch, Type ZM1 mill equipped with a $1 \mathrm{~mm}$ sieve) as well as the reversed-phase high-performance liquid chromatography (RP-HPLC) method was based on Wieser et al. [12] with slight modifications.

2.6. RP-HPLC. Perkin Elmer LC 200 chromatograph was used with a Supelco Discovery BIO Wide Pore C18 column (300 $\AA$ pore size, $5 \mu \mathrm{m}$ particle size, and $4.6 \times 250 \mathrm{~mm}$ i.d.). Solvent was composed of water containing $0.1 \%(\mathrm{v} / \mathrm{v})$ trifluoroacetic acid (TFA) and acetonitrile (ACN), while $20 \mu \mathrm{L}$ of sample was injected for analyses. Glutenin fractions were eluted with a linear gradient from $24 \%$ to $58 \%$ ACN over $30 \mathrm{~min}$ at $1 \mathrm{~mL} / \mathrm{min}$, using a column temperature of $50^{\circ} \mathrm{C}$. All samples were detected by UV absorbance at $210 \mathrm{~nm}$ in two replicates. The obtained chromatograms were analyzed by Total-Chrome software package (Perkin Elmer Instruments, USA). The peak areas (expressed in arbitrary units $=\mathrm{AU}$ ) under gliadins and glutenin chromatograms are used for further calculations.

2.7. Statistical Analysis. The data were statistically analyzed by STATISTICA 12.0 software (StatSoft Inc., USA, 2013). Descriptive statistics was used to explore the molecular weights and percentage amounts of gluten proteins and for that purpose mean values and coefficients of variation (CV) were calculated. Pearson correlation coefficients were calculated in order to explore correlations between different parameters determined by LoaC and RP-HPLC methods as well as to determine the degree of linearity within the working range of standards used in LoaC method.

\section{Results and Discussion}

3.1. Application of LoaC Method. The molecular weight reproducibility of HMW-GS (high molecular weight glutenin subunits) determined by LoaC method was evaluated by examining two replicates of each sample. Coefficient of variation $(\mathrm{CV})$ was calculated as a relative measure of error since it weights the standard deviation for the size of mean. The 
TABLE 1: Apparent sizes and quantification of individual HMW-GS subunits for all examined bread wheat cultivars by LoaC method and quantification of individual HMW-GS subunits by RP-HPLC.

\begin{tabular}{|c|c|c|c|c|c|c|}
\hline \multirow{2}{*}{ Subunits } & \multicolumn{2}{|c|}{ Molecular weight $(\mathrm{kDa})$} & \multicolumn{2}{|c|}{ Relative amount (\%) } & \multicolumn{2}{|c|}{ Relative amount (\%) } \\
\hline & Mean & $\mathrm{CV}(\%)$ & Mean & CV (\%) & Mean & CV (\%) \\
\hline $2 \& 5$ & 230.9 & 0.55 & 5.32 & 6.25 & - & - \\
\hline 2 & 230.9 & 1.00 & 3.51 & 37.74 & 10.29 & 7.03 \\
\hline 5 & 229.6 & 2.10 & 3.34 & 41.91 & 10.71 & 18.84 \\
\hline $5 \& 2 \& 9$ & - & - & - & - & 14.43 & 1.71 \\
\hline $5 \& 9$ & - & - & - & - & 10.16 & 1.06 \\
\hline $2^{*}$ & 212.6 & 3.08 & 1.93 & 64.82 & 1.47 & 25.43 \\
\hline 1 & 212.2 & 1.11 & 1.21 & 32.43 & 1.75 & 49.85 \\
\hline 7 & 178.0 & 2.41 & 3.92 & 59.37 & 9.32 & 15.38 \\
\hline $17+18(2)^{\mathrm{c}}$ & 160.6 & 2.03 & 0.99 & 27.98 & - & - \\
\hline 10 & 144.4 & 2.24 & 2.71 & 47.14 & 2.99 & 37.07 \\
\hline 8 & 134.8 & 1.36 & 0.50 & 44.77 & 2.16 & 26.31 \\
\hline 9 & 131.7 & 1.60 & 2.47 & 51.37 & 3.99 & 27.32 \\
\hline 12 & 130.0 & 0.00 & 0.79 & 16.75 & 3.86 & 26.25 \\
\hline $12 \& 9$ & 128.0 & 0.52 & 5.51 & 27.80 & - & - \\
\hline $17+18(1)^{\mathfrak{c}}$ & 124.8 & 2.83 & 1.67 & 14.66 & - & - \\
\hline 17 & - & - & - & - & 10.80 & 1.77 \\
\hline 18 & - & - & - & - & 4.67 & 4.53 \\
\hline
\end{tabular}

${ }^{\mathrm{a}}$ Expressed as relative amount: percentage of individual HMW area to total LMW + HMW area.

${ }^{\mathrm{b}}$ Expressed as relative amount: percentage of individual HMW area to total LMW + HMW area.

${ }^{\mathrm{c}}$ Subunits 17 and 18 were clearly distinguished by LoaC method, whereas by SDS-PAGE method these two subunits were overlapped (Marchetti-Deschmann et al., 2011) [8]. Therefore it was not possible to determine molecular weight of each separate subunit by LoaC method and they will be labelled as $17+18(1)$ and $17+18(2)$.

apparent sizes of glutenin subunits $2 \& 5,2,5,2^{*}, 1,7,17+18$, $10,8,9,12$, and $12 \& 9$ and their relative amounts are presented in Table 1. In general, the apparent sizes determined by LoaC method were at the same level as those obtained by MarchettiDeschmann et al. [8] using Protein 230 Plus Lab-on-a-Chip kit for glutenin subunits $2 \& 5,2,5,7$, and 10, whereas for $2^{*}, 9,12 \& 9$, and $17+18$ (1) subunits they were higher and for $1,17+18(2)$, and 8 subunits they were lower. Considering cultivars containing subunits 12 and 9, their peaks were barely resolved and only a shoulder peak was observed for subunit 9 with quite smaller area than subunit 12 . The similar situation was observed with cultivars which possess subunits 2 and 5 , where it was not possible to distinguish between these two subunits. The other authors had similar situation when examining wheat samples that contained subunit pairs 12 \& $18,16 \& 10,1 \& 4$ [7], and $12 \& 9$ [14]. The results were highly reproducible, since CVs of molecular weights were about or less than $2 \%$ for eleven determined subunits which is in accordance with results of other authors [6-8], except for glutenin subunits $2^{*}$ and $17+18$ (1) whose CVs were $3.08 \%$ and $2.83 \%$, respectively. These two values are also satisfactory since they are not higher than $5 \%$ which is in accordance with the results of Balázs et al. $[9,10]$.

The relative amount of some HMW-GS (2 \& 5 and $17+18$ (1)) fluctuated slightly among genotypes which possess these combinations of HMW-GS, whereas significant variations in the relative amount of other detected HMWGS were observed (Table 1). Therefore it could be possible to obtain different percentage in total sum of HMW-GS among cultivars where it is necessary to compare their quantity in detailed examination. The determination of the amount of HMW-GS is important for prediction of wheat quality parameters [15-17]. Furthermore, according to Rhazi et al. [7] the quantification of HMW-GS could be used to detect an overexpression of HMW-GS; for example, an overexpression of the subunit 7 is encountered in certain cultivars. Also, subunit 7 possesses one of the highest CVs of all examined cultivars in this study.

Molecular weight and quantification of individual HMWGS by the LoaC method of nine Croatian and Serbian bread wheat cultivars are represented in Tables 2 and 3, respectively. The most frequent HMW-GS combination in both assortments are 2*, $7+9$, and $5+10$ ("Divana," "Zlata," "Pobeda," "Bastijana," and "NS3-5299") for which the authors [18-20] suppose that, together with $\mathrm{N}, 7+9$, and $5+10$, HMW-GS combination dominates in European winter wheat cultivars. Beside this combination, HMW-GS combinations $7+9$ and $2+12$ ("Dragana," "Simonida," and "Zvezdana"); $2^{*}, 7+$ 8 , and $5+10$ ("Soissons" and "Felix"), and N, $7+9$, and $5+$ 10 ("Ljiljana" and "Etida") are also frequent in this study. When subunits separated by HMW-GS within assortment are compared with each other, it can be observed that HMWGS molecular weights are almost identical, except subunits $2^{*}$ and 5, whereas the highest variation in the HMW-GS quantities was found for subunits 7, 10,9, and 12 \& 9 (Tables 2 and $3)$. The average relative standard deviation of the peak timecorrected areas (CV) was $18.44 \%$ (data not shown) which is on the levels obtained by Balázs et al. [9]. Also, average 
TABLE 2: Apparent sizes and quantification of individual HMW-GS subunits of nine bread wheat cultivars grown in Croatia by LoaC method and quantification of individual HMW-GS subunits by RP-HPLC.

\begin{tabular}{|c|c|c|c|c|c|c|c|}
\hline \multirow{2}{*}{ Cultivar } & \multirow{2}{*}{ Subunits } & \multicolumn{2}{|c|}{ Molecular weight $(\mathrm{kDa})$} & \multicolumn{2}{|c|}{ Relative amount $(\%)^{\mathrm{a}}$} & \multicolumn{2}{|c|}{ Relative amount $(\%)^{\mathrm{b}}$} \\
\hline & & Mean & CV (\%) & Mean & CV (\%) & Mean & CV (\%) \\
\hline \multirow{5}{*}{ Soissons } & 5 & 228.1 & 1.43 & 2.54 & 16.82 & 11.64 & 0.00 \\
\hline & $2^{*}$ & 221.0 & 0.19 & 4.18 & 18.65 & 1.68 & 16.64 \\
\hline & 7 & 171.2 & 0.08 & 1.26 & 1.55 & 7.63 & 5.51 \\
\hline & 10 & 139.9 & 0.25 & 3.29 & 4.75 & 1.93 & 14.50 \\
\hline & 8 & 133.3 & 0.53 & 0.26 & 14.07 & 1.92 & 4.56 \\
\hline \multirow{5}{*}{ Felix } & 5 & 223.8 & 1.04 & 1.68 & 19.98 & 12.25 & 4.42 \\
\hline & $2^{*}$ & 202.2 & 0.73 & 1.07 & 7.07 & 1.42 & 11.31 \\
\hline & 7 & 171.9 & 1.15 & 1.47 & 1.33 & 10.25 & 1.18 \\
\hline & 10 & 140.3 & 0.76 & 1.95 & 18.56 & 1.95 & 1.03 \\
\hline & 8 & 133.2 & 0.74 & 0.39 & 0.66 & 2.53 & 11.12 \\
\hline \multirow{5}{*}{ Divana } & 5 & 226.8 & 1.87 & 3.17 & 32.06 & 11.21 & 6.49 \\
\hline & $2^{*}$ & 205.5 & 1.65 & 1.21 & 3.59 & 2.17 & 14.38 \\
\hline & 7 & 174.7 & 0.89 & 2.09 & 8.66 & 12.95 & 5.01 \\
\hline & 10 & 142.4 & 0.89 & 2.30 & 3.13 & 3.88 & 7.37 \\
\hline & 9 & 129.0 & 0.38 & 2.88 & 30.37 & 6.56 & 1.19 \\
\hline \multirow{5}{*}{ Zlata } & 5 & 229.8 & 1.38 & 3.07 & 30.43 & 6.77 & 5.34 \\
\hline & $2^{*}$ & 208.0 & 2.07 & 0.96 & 2.91 & 1.00 & 12.57 \\
\hline & 7 & 176.4 & 1.48 & 2.83 & 10.02 & 9.34 & 5.05 \\
\hline & 10 & 143.9 & 1.87 & 1.99 & 10.63 & 1.58 & 21.91 \\
\hline & 9 & 130.3 & 1.03 & 2.45 & 22.73 & 3.55 & 9.31 \\
\hline \multirow{5}{*}{ Seka } & 5 & 226.4 & 0.94 & 1.72 & 71.31 & 10.80 & 2.49 \\
\hline & 1 & 210.9 & 1.24 & 0.85 & 10.64 & 1.17 & 0.00 \\
\hline & 7 & 174.9 & 0.85 & 2.09 & 23.06 & 9.31 & 2.89 \\
\hline & 10 & 142.4 & 1.19 & 1.71 & 34.37 & 2.00 & 17.90 \\
\hline & 9 & 135.4 & 0.63 & 0.74 & 16.32 & 2.05 & 8.73 \\
\hline \multirow{4}{*}{ Vulkan } & 5 & 225.5 & 0.35 & 2.49 & 66.87 & 6.82 & 3.06 \\
\hline & 7 & 174.1 & 0.57 & 1.47 & 0.60 & 8.18 & 1.45 \\
\hline & 10 & 142.6 & 1.14 & 1.46 & 11.61 & 3.28 & 4.53 \\
\hline & 8 & 135.0 & 0.63 & 0.53 & 57.52 & 2.76 & 6.48 \\
\hline \multirow{5}{*}{ Renata } & 5 & 229.1 & 0.56 & 2.30 & 19.53 & 13.55 & 2.58 \\
\hline & 1 & 212.6 & 1.10 & 1.09 & 13.28 & 1.25 & 13.99 \\
\hline & 7 & 176.2 & 1.12 & 1.87 & 8.03 & 9.01 & 5.17 \\
\hline & 10 & 143.3 & 1.83 & 1.17 & 8.03 & 2.23 & 6.98 \\
\hline & 8 & 135.0 & 0.84 & 0.65 & 49.25 & 1.44 & 9.43 \\
\hline \multirow{7}{*}{ Aida } & 5 & 224.2 & 2.56 & 3.00 & 23.59 & 10.82 & 3.92 \\
\hline & $2^{*}$ & 209.3 & 1.62 & 0.83 & 20.23 & 1.30 & 24.38 \\
\hline & $17+18(2)$ & 160.6 & 2.03 & 0.99 & 27.98 & - & - \\
\hline & 10 & 140.8 & 1.66 & 1.78 & 10.74 & 2.37 & 12.53 \\
\hline & $17+18(1)$ & 124.8 & 2.83 & 1.67 & 14.66 & - & - \\
\hline & 17 & - & - & - & - & 10.80 & 1.77 \\
\hline & 18 & - & - & - & - & 4.67 & 4.53 \\
\hline \multirow{6}{*}{ Tihana } & 2 & 232.8 & 1.49 & 1.75 & 48.76 & 9.79 & 2.72 \\
\hline & 1 & 213.2 & 1.49 & 1.69 & 1.80 & 2.83 & 17.32 \\
\hline & 7 & 175.5 & 0.93 & 2.31 & 7.34 & 8.39 & 2.93 \\
\hline & $12 \& 9$ & 127.2 & 0.67 & 7.00 & 26.59 & - & - \\
\hline & 12 & - & - & - & - & 3.02 & 4.74 \\
\hline & 9 & - & - & - & - & 4.89 & 3.35 \\
\hline
\end{tabular}

\footnotetext{
${ }^{a}$ Expressed as relative amount: percentage of individual HMW area to total LMW + HMW area.
}

${ }^{\mathrm{b}}$ Expressed as relative amount: percentage of individual HMW area to total LMW + HMW area. 
TABLE 3: Apparent sizes and quantification of individual HMW-GS subunits of nine bread wheat cultivars grown in Serbia by LoaC method and quantification of individual HMW-GS subunits by RP-HPLC.

\begin{tabular}{|c|c|c|c|c|c|c|c|}
\hline \multirow{2}{*}{ Cultivar } & \multirow{2}{*}{ Subunits } & \multicolumn{2}{|c|}{ Molecular weight (kDa) } & \multicolumn{2}{|c|}{ Relative amount $(\%)^{\mathrm{a}}$} & \multicolumn{2}{|c|}{ Relative amount $(\%)^{\mathrm{b}}$} \\
\hline & & Mean & CV (\%) & Mean & $\mathrm{CV}(\%)$ & Mean & $\mathrm{CV}(\%)$ \\
\hline \multirow{4}{*}{ Etida } & 5 & 237.8 & 0.15 & 3.53 & 30.28 & 9.72 & 0.20 \\
\hline & 7 & 184.0 & 0.46 & 4.30 & 35.62 & 10.49 & 3.12 \\
\hline & 10 & 148.1 & 0.62 & 2.70 & 23.92 & 3.62 & 7.44 \\
\hline & 9 & 133.6 & 1.16 & 2.38 & 22.13 & 3.37 & 1.14 \\
\hline \multirow{5}{*}{ Ljiljana } & 5 & 233.4 & 1.27 & 4.58 & 20.94 & - & - \\
\hline & $5 \& 9$ & - & - & - & - & 10.16 & 1.06 \\
\hline & 7 & 183.8 & 1.23 & 6.50 & 13.02 & 9.91 & 0.73 \\
\hline & 10 & 147.8 & 0.67 & 4.52 & 9.30 & 5.27 & 1.02 \\
\hline & 9 & 131.1 & 0.70 & 1.12 & 14.79 & - & - \\
\hline \multirow{5}{*}{ Pobeda } & 5 & 232.1 & 0.79 & 5.68 & 9.24 & 11.79 & 2.66 \\
\hline & $2^{*}$ & 216.3 & 0.26 & 3.35 & 24.39 & 1.65 & 0.00 \\
\hline & 7 & 181.3 & 0.35 & 7.21 & 34.01 & 9.91 & 1.13 \\
\hline & 10 & 147.0 & 0.29 & 4.34 & 26.86 & 4.28 & 10.48 \\
\hline & 9 & 130.9 & 0.59 & 4.27 & 40.61 & 4.06 & 18.78 \\
\hline \multirow{5}{*}{ Bastijana } & 5 & 234.6 & 1.27 & 5.04 & 8.97 & 11.91 & 0.50 \\
\hline & $2^{*}$ & 216.4 & 0.39 & 1.07 & 66.38 & 1.65 & 1.21 \\
\hline & 7 & 182.5 & 0.08 & 7.51 & 19.71 & 8.74 & 2.74 \\
\hline & 10 & 147.9 & 0.29 & 4.89 & 12.12 & 2.27 & 7.91 \\
\hline & 9 & 131.8 & 0.16 & 3.62 & 16.12 & 3.62 & 0.55 \\
\hline \multirow{5}{*}{ NS3-5299 } & 5 & 233.5 & 1.91 & 4.58 & 9.12 & 11.25 & 0.36 \\
\hline & $2^{*}$ & 218.5 & 0.29 & 1.75 & 18.35 & 1.25 & 3.68 \\
\hline & 7 & 182.7 & 1.47 & 4.18 & 34.82 & 7.67 & 1.05 \\
\hline & 10 & 147.8 & 0.57 & 1.84 & 0.10 & 4.15 & 0.97 \\
\hline & 9 & 131.5 & 1.61 & 2.32 & 24.33 & 3.95 & 1.02 \\
\hline \multirow{5}{*}{ Simonida } & 2 & 229.1 & 0.65 & 4.24 & 2.90 & 9.50 & 1.33 \\
\hline & 7 & 177.9 & 0.32 & 3.04 & 11.50 & 6.69 & 1.35 \\
\hline & $12 \& 9$ & 128.3 & 0.17 & 3.96 & 16.46 & - & - \\
\hline & 9 & - & - & - & - & 3.95 & 0.91 \\
\hline & 12 & - & - & - & - & 5.24 & 3.10 \\
\hline \multirow{5}{*}{ Dragana } & 2 & 229.8 & 0.46 & 3.15 & 8.06 & 10.75 & 1.54 \\
\hline & 7 & 177.0 & 0.28 & 6.59 & 1.13 & 10.04 & 2.88 \\
\hline & $12 \& 9$ & 127.9 & 0.33 & 6.25 & 6.39 & - & - \\
\hline & 9 & - & - & - & - & 4.25 & 0.49 \\
\hline & 12 & - & - & - & - & 4.20 & 3.93 \\
\hline \multirow{5}{*}{ Zvezdana } & 2 & 232.2 & 0.70 & 4.91 & 3.88 & 11.11 & 1.38 \\
\hline & 7 & 179.1 & 0.20 & 5.17 & 2.60 & 9.42 & 0.61 \\
\hline & $12 \& 9$ & 128.6 & 0.06 & 4.83 & 21.54 & & \\
\hline & 9 & - & - & - & - & 3.63 & 4.22 \\
\hline & 12 & - & - & - & - & 2.95 & 1.30 \\
\hline \multirow{7}{*}{ Nevesinjska } & $5 \& 2$ & 230.9 & 0.55 & 5.32 & 6.25 & - & - \\
\hline & $5 \& 2 \& 8$ & - & - & - & - & 14.43 & 1.71 \\
\hline & $2^{*}$ & 216.5 & 0.36 & 2.96 & 11.42 & 1.11 & 3.72 \\
\hline & 7 & 183.4 & 0.04 & 6.73 & 17.34 & 10.52 & 1.76 \\
\hline & 10 & 147.0 & 0.43 & 4.05 & 6.18 & 3.04 & 0.68 \\
\hline & 8 & 137.7 & 0.21 & 0.67 & 9.24 & - & - \\
\hline & 12 & 130.0 & 0.00 & 0.79 & 16.75 & - & - \\
\hline
\end{tabular}

\footnotetext{
${ }^{a}$ Expressed as relative amount: percentage of individual HMW area to total LMW + HMW area.
}

${ }^{\mathrm{b}}$ Expressed as relative amount: percentage of individual HMW area to total LMW + HMW area. 
values of relative standard deviation obtained for several cultivars examined in this study were on the same level as in previous research [21], in which only one cultivar had been analysed.

Calibration curves of all determined chips were linear within the working range of standards from $4.5 \mathrm{kDa}$ to $240 \mathrm{kDa}$. Squared correlation coefficients $\left(R^{2}\right)$ showed good linearity in the range from 0.9448 to 0.9455 , whereas LOD and LOQ were not determined in this paper since they were the topics of the paper previously published by Živančev et al. [21], with detailed explanation of glutenin subunits determination by LoaC method.

3.2. Comparison of LoaC and HPLC Methods. The quantification of HMW-GS by RP-HPLC (Tables 1, 2, and 3) showed why this method has been routinely applied in cereal chemistry for several decades for identifying particular glutenin subunits related to bread-making quality [22-24]. The relative amount of all HMW-GS determined by RPHPLC method was higher than that determined by LoaC method (Table 1) except for glutenin subunit $2^{*}$. Also, in most cases the CVs of HMW-GS gained by RP-HPLC were lower than those gained by LoaC method (Table 1). Only for glutenin subunits 1 and $12 \mathrm{CV}$ s gained by LoaC method were lower than those gained by RP-HPLC method. LoaC had advantage in determination of HMW-GS in two cases since RP-HPLC method was not able to resolve subunit 5 from subunits 8 and 9 of cultivars "Nevesinjska" and "Ljiljana," respectively (Table 3).

Quantitative analysis of gluten proteins by LoaC and RPHPLC methods (Table 4) indicates that method of analysis has substantial impact on gained result, since number of bands/peaks among examined cultivars noticeably depend on used method. In addition, more comparable results were obtained when determining glutenin subunits (Figures 1 and 2) than when determining gliadin subunits. Considerably higher number of gliadin peaks was gained by RP-HPLC method than by LoaC method. Balázs et al. [10] had the same observation, stating that only few gliadin peaks could be integrated automatically by software, and therefore they used manual integration of gliadin peaks in their research. Also, peaks gained by LoaC method were considerably wider and less sharp (Figure 3) which makes their determination difficult in comparison with RP-HPLC method (Figure 4). The reason for this could be the fact that Protein 230 Plus Lab-on-a-Chip kit was used for gliadin measurements instead of Protein 80 Lab-on-a-Chip kit which can provide better band separations of smaller molecular weights by increasing the separation time of proteins with lesser MWs. Another cause of difference obtained could be the dissimilar sample preparation-wholemeal flour for RP-HPLC samples and white flour (mostly from kernel endosperm) for LoaC samples. These exact determinations are of great importance especially because of gliadins' sensitivity to climate changes [25] and for $\omega$-gliadins (their apparent molecular weights gained by LoaC were $120-125 \mathrm{kDa}$ ) which are synthesized in unusually high proportion when sulphur is deficient

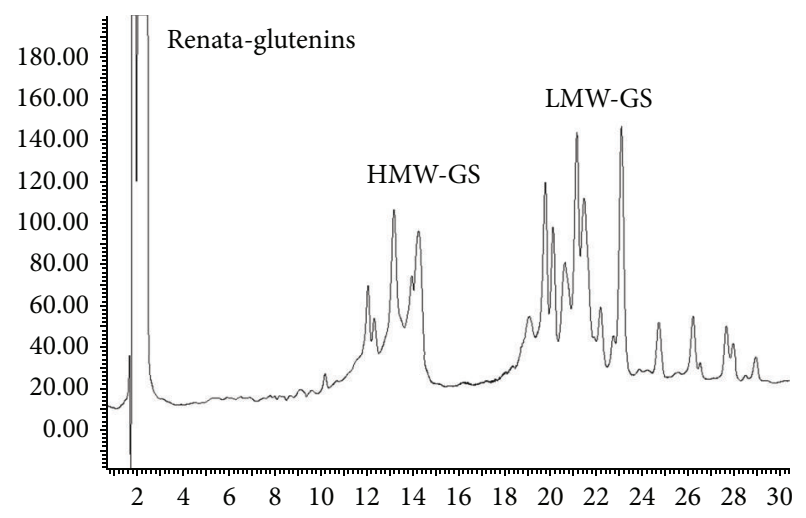

FIgURE 2: Chromatogram of glutenins of cultivar "Renata."

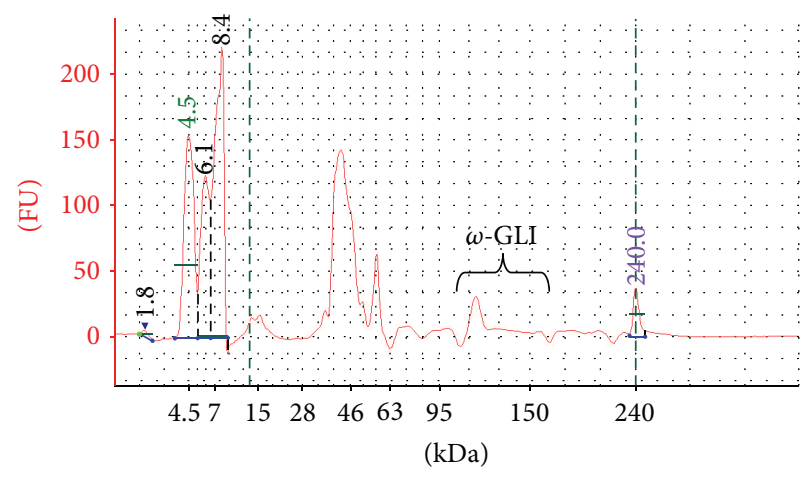

FIGURE 3: Electrophoregram of gliadins of cultivar "Aida."

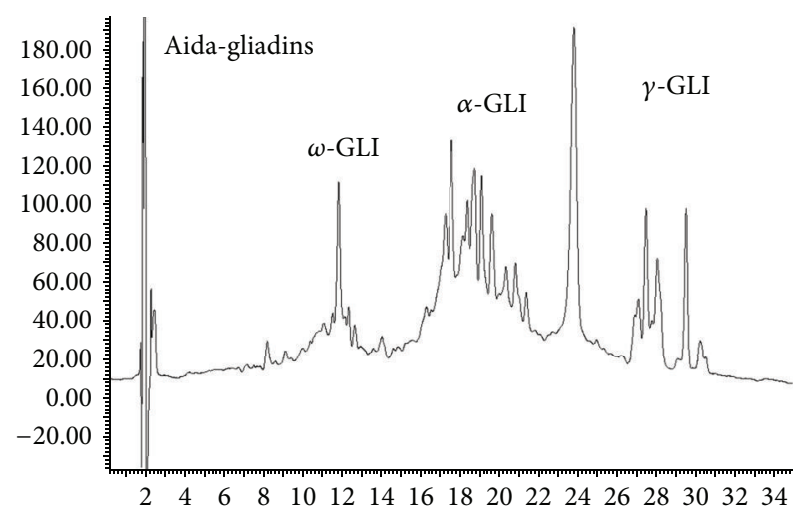

FIGURE 4: Chromatogram of gliadins of cultivar "Aida."

during grain filling [26] and at high temperatures with better agricultural practices [27].

The correlation coefficients between number of bands/ peaks of gliadin subunits and glutenin subunits determined by LoaC and RP-HPLC methods and between relative amounts of gliadin subunits $(\alpha+\gamma$ and $\omega)$ and glutenin subunits (LMW and HWM) are shown in Tables 5 and 6, respectively. Regarding correlation coefficients between number of gliadin and glutenin subunits peaks determined by both methods (Table 5), HMW showed strong correlation $(P \leq 0.001)$. There were significant correlations $(P \leq 0.05)$ 
TABLE 4: Comparison between number of bands as determined by LoaC and number of peaks as determined by RP-HPLC.

\begin{tabular}{|c|c|c|c|c|c|c|c|c|c|c|c|c|}
\hline \multirow{3}{*}{ Cultivar } & \multicolumn{6}{|c|}{ LoaC number of bands } & \multicolumn{6}{|c|}{ RP-HPLC number of peaks } \\
\hline & \multicolumn{3}{|c|}{ GLI } & \multicolumn{3}{|c|}{ GLU } & \multicolumn{3}{|c|}{ GLI } & \multicolumn{3}{|c|}{ GLU } \\
\hline & Total & Omega & $\begin{array}{l}\text { Alpha + } \\
\text { Gamma }\end{array}$ & Total & HMW & LMW & Total & Omega & $\begin{array}{l}\text { Alpha + } \\
\text { Gamma }\end{array}$ & Total & HMW & LMW \\
\hline Soissons & 33 & 8 & 25 & 22 & 5 & 17 & 36 & 9 & 27 & 20 & 5 & 15 \\
\hline Divana & 25 & 6 & 19 & 20 & 5 & 15 & 39 & 10 & 29 & 21 & 5 & 16 \\
\hline Seka & 30 & 6 & 24 & 19 & 5 & 14 & 37 & 9 & 28 & 21 & 5 & 16 \\
\hline Vulkan & 29 & 8 & 21 & 20 & 4 & 16 & 38 & 10 & 28 & 20 & 4 & 16 \\
\hline Renata & 26 & 6 & 20 & 21 & 5 & 16 & 39 & 11 & 28 & 21 & 5 & 16 \\
\hline Zlata & 29 & 6 & 23 & 21 & 5 & 16 & 39 & 10 & 29 & 23 & 5 & 18 \\
\hline Aida & 25 & 6 & 17 & 20 & 5 & 15 & 40 & 10 & 30 & 22 & 5 & 17 \\
\hline Felix & 28 & 6 & 22 & 22 & 5 & 17 & 41 & 10 & 31 & 21 & 5 & 16 \\
\hline Tihana & 28 & 6 & 22 & 19 & 5 & 14 & 38 & 8 & 30 & 23 & 5 & 18 \\
\hline Dragana & 26 & 6 & 20 & $18^{\mathrm{a}}$ & $3^{\mathrm{a}}$ & $15^{\mathrm{a}}$ & 34 & 7 & 27 & 22 & 4 & 18 \\
\hline Ljiljana & 26 & 6 & 20 & 20 & 4 & 16 & 35 & 8 & 27 & 21 & 4 & 17 \\
\hline Pobeda & 30 & 7 & 23 & 21 & 5 & 16 & 36 & 8 & 28 & 22 & 5 & 17 \\
\hline Bastijana & 30 & 6 & 24 & 21 & 5 & 16 & 33 & 8 & 25 & 23 & 5 & 18 \\
\hline Nevesinjska & 26 & 6 & 20 & $22^{\mathrm{b}}$ & $6^{\mathrm{b}}$ & $35^{\mathrm{b}}$ & 35 & 7 & 28 & 24 & 5 & 19 \\
\hline Simonida & 28 & 6 & 22 & $19^{\mathrm{a}}$ & $3^{\mathrm{a}}$ & $16^{\mathrm{a}}$ & 33 & 10 & 23 & 20 & 4 & 16 \\
\hline Etida & 27 & 6 & 21 & 20 & 4 & 16 & 30 & 8 & 22 & 21 & 4 & 17 \\
\hline Zvezdana & 31 & 6 & 25 & $19^{\mathrm{a}}$ & $3^{\mathrm{a}}$ & $16^{\mathrm{a}}$ & 31 & 8 & 23 & 21 & 4 & 17 \\
\hline NS3-5299/2 & 28 & 7 & 21 & 22 & 5 & 17 & 29 & 8 & 21 & 24 & 5 & 19 \\
\hline
\end{tabular}

${ }^{\mathrm{a}}$ Overlapping of subunits 9 and 12 .

${ }^{\mathrm{b}}$ Overlapping of subunits 2 and 5 .

TABLE 5: Correlation coefficients between number of bands/peaks of gliadin and glutenin subunits determined by LoaC and RP-HPLC methods.

\begin{tabular}{|c|c|c|c|c|c|c|}
\hline & $\begin{array}{l}\text { LoaC GLI } \\
\text { total }\end{array}$ & $\begin{array}{l}\text { LoaC } \\
\text { GLI } \omega\end{array}$ & LoaC GLI $\alpha+\gamma$ & $\begin{array}{l}\text { LoaC GLU } \\
\text { total }\end{array}$ & $\begin{array}{c}\text { LoaC GLU } \\
\text { HMW }\end{array}$ & $\begin{array}{l}\text { LoaC GLU } \\
\text { LMW }\end{array}$ \\
\hline HPLC GLI total & -0.20 & & & & & \\
\hline HPLC GLI $\omega$ & & 0.07 & & & & \\
\hline HPLC GLI $\alpha+\gamma$ & & & -0.25 & & & \\
\hline HPLC GLU total & & & & 0.31 & & \\
\hline HPLC GLU HMW & & & & & $0.88^{* * *}$ & \\
\hline HPLC GLU LMW & & & & & & 0.41 \\
\hline
\end{tabular}

Values are means $(N=18) ;{ }^{* * *} P \leq 0.001$.

TABLE 6: Correlation coefficients between relative amounts of gliadin subunits $(\alpha+\gamma$ and $\omega)$ and glutenin subunits (LMW and HWM) determined by LoaC and RP-HPLC methods ${ }^{\mathrm{a}}$.

\begin{tabular}{|c|c|c|c|c|c|c|}
\hline & $\% \omega$ LoaC $^{b}$ & $\begin{array}{l}\% \alpha+\gamma \\
\text { LoaC }^{\mathrm{b}}\end{array}$ & $\begin{array}{l}\text { \% HMW } \\
\text { LoaC }^{\mathrm{c}}\end{array}$ & $\begin{array}{c}\text { \% LMW } \\
\text { LoaC }^{c}\end{array}$ & $\begin{array}{l}\text { \% HMW/LMW } \\
\text { LoaC }\end{array}$ & $\begin{array}{c}\text { HMW LoaC } \\
\text { total }^{\mathrm{d}}\end{array}$ \\
\hline$\% \omega$ HPLC $^{b}$ & -0.127 & & & & & \\
\hline$\% \alpha+\gamma$ HPLC $^{\mathrm{b}}$ & & -0.118 & & & & \\
\hline \% HMW HPLC ${ }^{\mathrm{c}}$ & & & $0.338^{*}$ & & & \\
\hline \% LMW HPLC & & & & $0.341^{*}$ & & \\
\hline \% HMW/LMW HPLC & & & & & 0.308 & \\
\hline$\%$ HMW HPLC total ${ }^{\mathrm{d}}$ & & & & & & $0.554^{* * *}$ \\
\hline
\end{tabular}

${ }^{\mathrm{a}}$ Values are means $(N=36) ;{ }^{*} P \leq 0.05,{ }^{* * *} P \leq 0.001$.

${ }^{\mathrm{b}}$ Expressed as relative amount: percentage of individual $\alpha+\gamma$ and $\omega$ area to total area of gliadins.

${ }^{c}$ Expressed as relative amount: percentage of individual LMW and HMW area to total area of glutenins.

${ }^{\mathrm{d}}$ Expressed as relative amount: percentage of individual HMW area to total HMW area. 
TABLE 7: Quantification of individual HMW-GS subunits for all examined bread wheat cultivars by RP-HPLC and LoaC methods.

\begin{tabular}{lcccc}
\hline Subunits & \multicolumn{2}{c}{ LoaC } & \multicolumn{2}{c}{ RP-HPLC } \\
& $\begin{array}{c}\text { Amount } \\
(\%)^{*}\end{array}$ & CV (\%) & $\begin{array}{c}\text { Amount } \\
(\%)^{*}\end{array}$ & CV (\%) \\
\hline $5 \& 2$ & 34.0 & 5.62 & 40.0 & 1.06 \\
2 & 25.8 & 40.69 & 37.2 & 7.42 \\
5 & 27.5 & 27.16 & 38.9 & 15.75 \\
$2^{*}$ & 13.8 & 68.72 & 5.3 & 18.71 \\
1 & 13.4 & 14.81 & 6.3 & 44.60 \\
7 & 27.6 & 29.45 & 34.0 & 13.37 \\
10 & 21.9 & 30.25 & 10.9 & 38.90 \\
8 & 6.4 & 49.85 & 8.8 & 35.21 \\
9 & 17.6 & 26.67 & 13.4 & 22.77 \\
$12 \& 9$ & 40.4 & 25.20 & 29.2 & 15.87 \\
\hline
\end{tabular}

${ }^{*}$ Expressed as relative amount: percentage of individual HMW area to total HMW area.

between percentages of HMW and LMW determined by both methods, whereas strong correlation $(R=0.554, P \leq 0.001)$ was obtained between total amounts of HMW (Table 6). Better correlations for LMW were not obtained probably because all subunits could not be separated and quantified due to closeness of large number of subunits [10].

Table 7 illustrates the comparison of the quantitative data of cultivars HMW-GS determined by LoaC and RPHPLC. The quantitative LoaC data, when expressed as a percentage of total HMW-GS peak area, were diverse to those determined by RP-HPLC. The main difference existed among amounts and CVs of HMW-GS with high molecular weight $\left(2,5,2^{*}\right.$, and 1$)$, whereas the rest of HMW-GS showed slightly higher similarity. However, the main disadvantage of RPHPLC method when compared to LoaC method represents separation time which limits number of analysed samples, whereas gliadin peaks resolution and lower peaks number gained by LoaC method are shortcoming in comparison to RP-HPLC method.

\section{Conclusions}

In conclusion, strong correlation $(P \leq 0.001)$ was found between numbers of HMW glutenin peaks determined by LoaC and RP-HPLC methods in this study. The existence of significant correlations $(P \leq 0.05)$ between percentages of HMW and LMW glutenin subunits calculated with regard to total HMW + LMW area was also demonstrated. Moreover, when percentages of individual HMW areas were calculated with regard to total HMW area, even more significant correlation was found $(P \leq 0.001)$. RP-HPLC method showed superiority in determination of gliadins since higher numbers and better resolution of gliadin peaks were gained by RP-HPLC method than by LoaC method. For further research of gliadins by LoaC method it is necessary to use Protein 80 Lab-on-a-Chip kit which can provide better band separations of smaller molecular weights. Sample preparation should be unified in further researches in order to achieve better correlation between results obtained by these methods.

\section{Conflict of Interests}

The authors declare that there is no conflict of interests regarding the publication of this paper.

\section{Acknowledgments}

This work was supported by the Ministry of Education, Science and Technological Development of the Republic of Serbia within the Project of technological development no. TR 31007 (2011-2014) and bilateral cooperation between Serbia and Croatia-Genetic polymorphism of gluten proteins and its relationship to bread-making quality of wheat (Triticum aestivum L.). Dr. Nikola Hristov from Institute of Field and Vegetable Crops (Novi Sad, Serbia) is also acknowledged for providing one set of examined cultivars.

\section{References}

[1] H. Goetz, M. Kuschel, T. Wulff et al., "Comparison of selected analytical techniques for protein sizing, quantitation and molecular weight determination," Journal of Biochemical and Biophysical Methods, vol. 60, no. 3, pp. 281-293, 2004.

[2] J. S. Hey, "Advances in microscale protein fractionation and analysis," The American Biotechnology Laboratory, vol. 25, no. 1, pp. 12-16, 2007.

[3] M. Kuschel, T. Neumann, P. Barthmaier, and M. Kratzmeier, "Use of lab-on-a-Chip technology for protein sizing and quantitation," Journal of Biomolecular Techniques, vol. 13, no. 3, pp. 172-178, 2002.

[4] A. M. Torbica, D. R. Živančev, Z. T. Nikolić, V. B. Đorđević, and B. G. Nikolovski, "Advantages of the lab-on-a-chip method in the determination of the kunitz trypsin inhibitor in soybean varieties," Journal of Agricultural and Food Chemistry, vol. 58, no. 13, pp. 7980-7985, 2010.

[5] S. Uthayakumaran, I. L. Batey, and C. W. Wrigley, "On-the-spot identification of grain variety and wheat-quality type by Labon-a-chip capillary electrophoresis," Journal of Cereal Science, vol. 41, no. 3, pp. 371-374, 2005.

[6] S. Uthayakumaran, Y. Listiohadi, M. Baratta, I. L. Batey, and C. W. Wrigley, "Rapid identification and quantitation of highmolecular-weight glutenin subunits," Journal of Cereal Science, vol. 44, no. 1, pp. 34-39, 2006.

[7] L. Rhazi, A.-L. Bodard, B. Fathollahi, and T. Aussenac, "High throughput microchip-based separation and quantitation of high-molecular-weight glutenin subunits," Journal of Cereal Science, vol. 49, no. 2, pp. 272-277, 2009.

[8] M. Marchetti-Deschmann, A. Lehner, V. Peterseil, F. Sövegjarto, R. Hochegger, and G. Allmaier, "Fast wheat variety classification by capillary gel electrophoresis-on-a-chip after single-step onegrain high molecular weight glutenin extraction," Analytical and Bioanalytical Chemistry, vol. 400, no. 8, pp. 2403-2414, 2011.

[9] G. Balázs, I. Baracskai, M. Nádosi, A. Harasztos, F. Békés, and S. Tömösközi, "Lab-on-a-chip technology in cereal science: analytical properties and possible application areas," Acta Alimentaria, vol. 41, no. 1, pp. 73-85, 2012.

[10] G. Balázs, S. Tömösközi, A. Harasztos et al., "Advantages and limitation of lab-on-a-chip technique in the analysis of wheat 
proteins," Cereal Research Communications, vol. 40, no. 4, pp. 562-572, 2012.

[11] J. F. Panozzo, H. A. Eagles, and M. Wootton, "Changes in protein composition during grain development in wheat," Australian Journal of Agricultural Research, vol. 52, no. 4, pp. 485-493, 2001.

[12] H. Wieser, S. Antes, and W. Seilmeier, "Quantitative determination of gluten protein types in wheat flour by reversed-phase high-performance liquid chromatography," Cereal Chemistry, vol. 75, no. 5, pp. 644-650, 1998.

[13] H. Wieser and W. Seilmeier, "The influence of nitrogen fertilisation on quantities and proportions of different protein types in wheat flour," Journal of the Science of Food and Agriculture, vol. 76, no. 1, pp. 49-55, 1998.

[14] H. Wieser and G. Zimmermann, "Importance of amounts and proportions of high molecular weight subunits of glutenin for wheat quality," European Food Research and Technology, vol. 210, no. 5, pp. 324-330, 2000.

[15] M. Rakszegi, G. Pastori, H. D. Jones et al., “Technological quality of field grown transgenic lines of commercial wheat cultivars expressing the 1Ax1 HMW glutenin subunit gene," Journal of Cereal Science, vol. 47, no. 2, pp. 310-321, 2008.

[16] D. Horvat, Ž. Kurtanjek, G. Drezner, G. Šimić, and D. Magdić, "Effect of HMM glutenin subunits on wheat quality attributes," Food Technology and Biotechnology, vol. 47, no. 3, supplement 1, pp. 253-259, 2009.

[17] D. Horvat, N. Crossed D. Signukić, D. Magdić et al., "Characterization of bread wheat cultivars (Triticum aestivum L.) by glutenin proteins," Cereal Research Communications, vol. 41, no. 1, pp. 133-140, 2013.

[18] M. Tohver, "High molecular weight (HMW) glutenin subunit composition of some Nordic and Middle European wheats," Genetic Resources and Crop Evolution, vol. 54, no. 1, pp. 67-81, 2007.

[19] S. Denčić, D. Obreht, B. Kobiljski, S. Štatkić, and B. Bede, "Genetic determination of bread making quality in wheat," in Proceedings of the 43rd Croatian and 3rd International Symposium on Agriculture, pp. 278-281, Opatija, Croatia, February 2008.

[20] N. Tsenov, D. Atanasova, I. Todorov, I. Ivanova, and I. Stoeva, "Allelic diversity in Bulgarian winter wheat varieties based on polymorphism of glutenin subunit composition," Cereal Research Communication, vol. 37, pp. 551-558, 2009.

[21] D. R. Živančev, B. G. Nikolovski, A. M. Torbica, J. S. Mastilović, and N. H. Dukić, "Lab-on-a-chip method uncertainties in determination of high-molecular- weight glutenin subunits," Chemical Industry and Chemical Engineering Quarterly, vol. 19, no. 4, pp. 553-561, 2013.

[22] B. A. Marchylo, J. E. Kruger, and D. W. Hatcher, "Quantitative reversed-phase high-performance liquid chromatographic analysis of wheat storage proteins as a potential quality prediction tool," Journal of Cereal Science, vol. 9, no. 2, pp. 113-130, 1989.

[23] K. Dong, C. Y. Hao, A. L. Wang, M. H. Cai, and Y. M. Yan, "Characterization of HMW glutenin subunits in bread and tetraploid wheats by reversed-phase high-performance liquid chromatography," Cereal Research Communications, vol. 37, no. 1, pp. 65-73, 2009.

[24] L. Gao, W. Ma, J. Chen et al., "Characterization and comparative analysis of wheat high molecular weight glutenin subunits by SDS-PAGE, RP-HPLC, HPCE, and MALDI-TOF-MS," Journal of Agricultural and Food Chemistry, vol. 58, no. 5, pp. 2777-2786, 2010 .
[25] R. A. Graybosch, C. J. Peterson, P. S. Baenziger, and D. R. Shelton, "Environmental modification of hard red winter wheat flour protein composition," Journal of Cereal Science, vol. 22, no. 1, pp. 45-51, 1995.

[26] S. Uthayakumaran, F. J. Zhao, D. Sivri, M. Roohani, I. L. Batey, and C. W. Wrigley, "Defect identification in wheat grain by micro-fluidic electrophoresis: sulfur deficiency and bug damage," Cereal Chemistry, vol. 84, no. 4, pp. 301-303, 2007.

[27] F. M. DuPont, S. Altenbach, R. Chan, K. Cronin, and D. Lieu, "Interactions between fertilizer, temperature and drought in determining flour composition and quality for bread wheat," in Wheat Gluten, P. R. Shewry and A. S. Tatham, Eds., pp. 488-491, Gluten Royal Society of Chemistry, Cambridge, UK, 2000. 

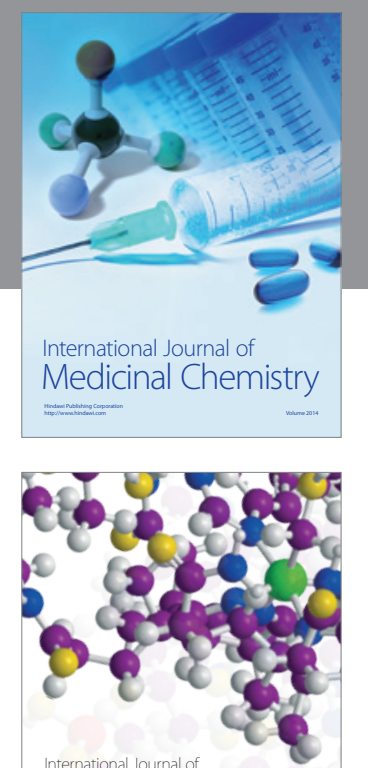

\section{Carbohydrate} Chemistry

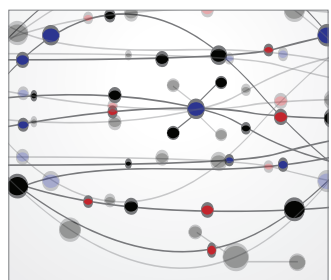

The Scientific World Journal
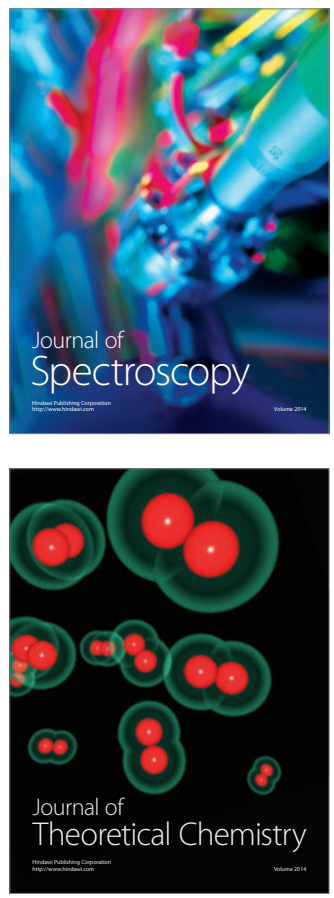
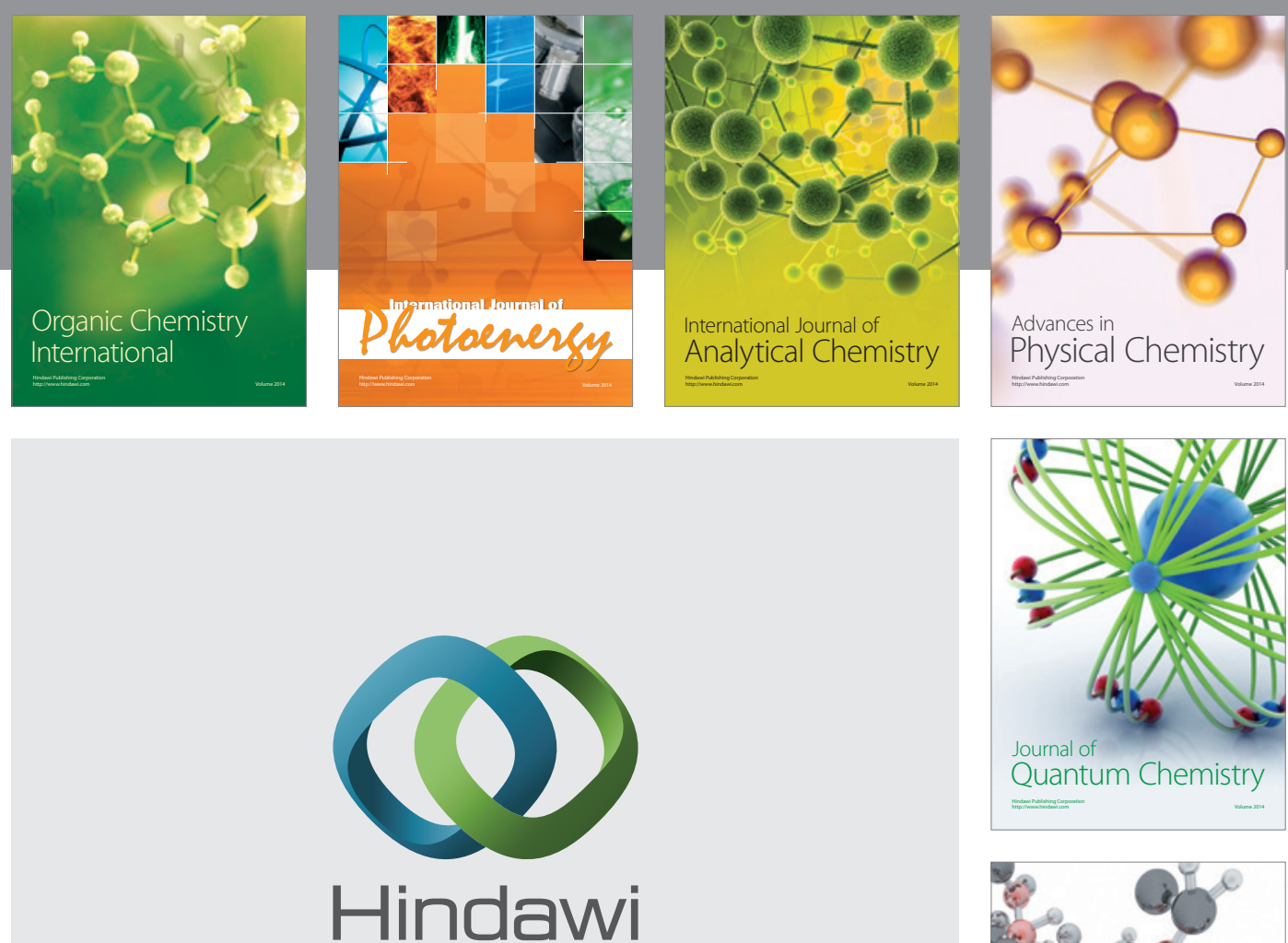

Submit your manuscripts at

http://www.hindawi.com

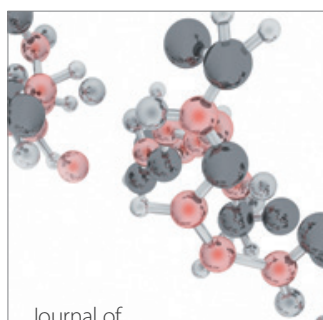

Analytical Methods

in Chemistry

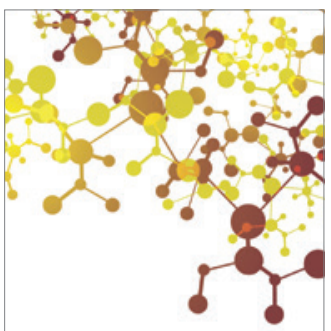

Journal of

Applied Chemistry

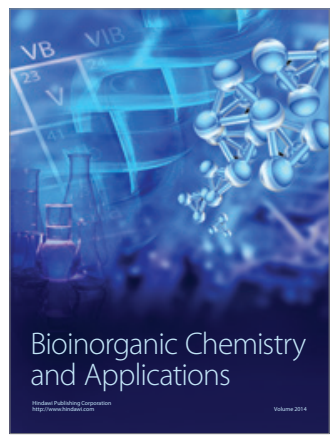

Inorganic Chemistry
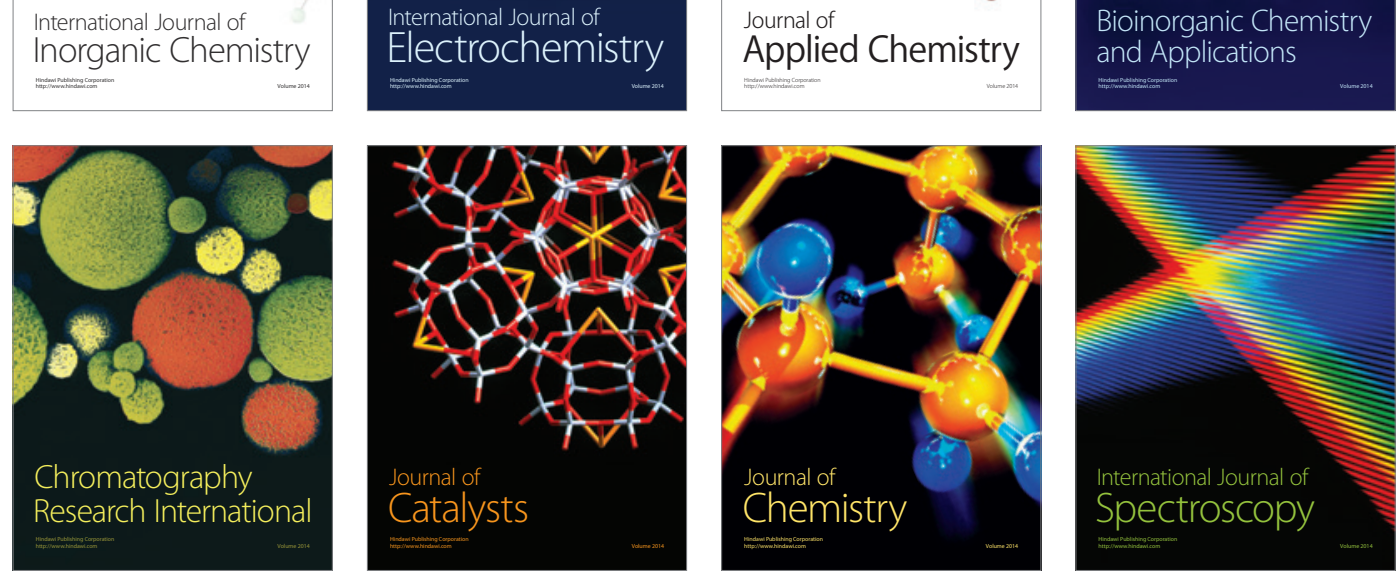